\title{
Mathematics teacher knowledge: mathematics in the foreground
}

\author{
Despina Potari
}

Published online: 11 March 2014

(C) Springer Science+Business Media Dordrecht 2014

The four research reports published in this issue of JMTE study teacher knowledge focusing mainly on its mathematical dimension. Issues concerning the characteristics of teacher knowledge for mathematics teaching especially at secondary level as well as the interplay between mathematics and pedagogical knowledge emerge.

In the first article, Sarah Bleiher, Denisse Thompson and Mile Krajcevski study prospective secondary mathematics teachers' (PSMT) knowledge of mathematical proof focusing on how they validate students' arguments and the feedback they provide. In particular, 34 prospective secondary mathematics teachers validated high school students' arguments before and after implementation of a set of activities in a mathematics methods course. The authors adopt Stylianides' (2007) position of proof as a mathematical argument that is a connected sequence of assertions for or against a mathematical claim with certain characteristics such as accepted statements, modes of argumentation and modes of argument representation. In their design of the instructional activities, they took into account two difficulties reported in the literature about proof validation: the focus on local specifics of an argument overlooking the global logical structure and the tendency to use an empirical inductive proof scheme.

The research questions are related to the effectiveness of the instructional activities on PSMT's validation skills and to the type of errors they identify. The results indicate that PSMT were successful at judging the validity of an argument in the pre- and posttest. Concerning the errors to which they attend, it appeared that they did not any longer hold an empirical proof scheme. Although the intervention seemed to have an impact on PSMT's understanding of proof, using indirect methods seemed to be difficult.

Prospective secondary mathematics teachers are also the focus of the second article by Jill Adler, Sarmin Hossain, Mary Stevenson, John Clarke, Rosa Archer and Barry Grantham who study how PSMT experience mathematics in a course (Mathematics Enhancement Course-MEC) addressing mathematics in 'depth.' The course is offered in a range of institutions in England and provides an alternative route to mathematics teaching for

D. Potari $(\bowtie)$

Department of Mathematics, University of Athens, Panepistimioupolis, 15784 Athens, Greece e-mail: dpotari@math.uoa.gr 
graduates who do not have a mathematics-related degree. The authors define the notions of 'deep subject knowledge' and 'mathematics for teaching' and clarify their own position. Adopting a social practice perspective, they consider MEC as a social practice where the students are learning to talk in and about 'understanding mathematics in depth.' The research questions that guided the study focused on how PSMT experience mathematics in MEC and its relation to pedagogy.

The authors used in-depth interviews with 18 MEC students selected from three different institutions at the end of the program. From the analysis of two interview questions, it appeared that students viewed MEC as an 'intense' mathematics course where they revisited school mathematics in new ways and they also learned new mathematics at a high level.

There was also evidence that students recognize deep mathematical knowledge as reasoning, connectedness and mathematical dispositions that characterize what mathematics knowledge for teaching includes. The authors conclude that such form of knowledge that is developed in the practice of teaching can also be developed at pre-service level.

The article of Holt Wilson, Paola Sztajn, Cyndi Edgington and Jere Confrey refers to a design experiment in the context of a professional development program aiming to support teacher learning of the equipartitioning learning trajectory. The authors use Ball's framework of mathematics knowledge for teaching (MKT) that they reinterpret it in the case of learning trajectories. The main research question concerns the ways teachers used their MKT to participate in discussions around professional learning tasks designed to support their learning of a learning trajectory. Three teachers were selected for the study on the basis of their responses on two assessment tests. The data consisted of video recordings of whole group discussions for four professional learning task sequences where the three teachers participated. Their findings suggest that teachers developed both pedagogical content knowledge (PCK) and subject-matter knowledge (SMK). In lower levels of the learning trajectory, the discussion focused only to pedagogical issues while in upper levels discussions seemed to shift from PCK to SMK. There is also evidence that teachers' MKT mediated their participation in discussions about subject matter. In particular, each teacher participated in different ways in the discussion according to her/his mathematics knowledge for teaching of equipartitioning and rational numbers. The authors conclude that teachers' participation in professional learning tasks about a learning trajectory impacts both their pedagogical and subject-matter knowledge.

The last article by Karthigeyan Subramaniam refers to prospective secondary mathematics teachers' pedagogical knowledge for teaching the estimation of length measurements. The author considers pedagogical knowledge for teaching as a highly contextual and interactive process between the teacher, the students and the mathematical content. In this process, beliefs about mathematics teaching and learning also play an important role. Benchmarks for measurement estimation are important symbolic representations used to transform the mathematics content of length measurement estimation.

The study was carried out in the context of a secondary mathematics methods course in the USA aiming to provide an in-depth concentration on mathematical and pedagogical content knowledge required for teaching at secondary level. Six prospective teachers from this course participated in the study. Data consisted of electronic journal responses to preand post-interview questions at the beginning and at the end of the study, observations, anecdotal and verbal data of the participants' engagement in a measurement estimation activity and work samples.

The findings indicate that prospective teachers used benchmarks for estimation and developed meaningful representations of nonstandard units that enabled them to estimate 
length. However, prospective teachers' pedagogical knowledge of teaching did not include benchmarks even after their engagement in the measurement estimation activity. Hands-on activities appeared to be a key teaching and learning strategy for estimation, a belief that seemed to constrain prospective teachers transforming their personal experiences and strategies with measurement estimation to teaching ideas.

\section{Reference}

Stylianides, A. J. (2007). Proof and proving in school mathematics. Journal for Research in Mathematics Education, 38, 289-321. 